\title{
An Updated Multilocus Phylogeny of the Lumbricidae (Annelida: Clitellata: Oligochaeta) Earthworms
}

Marcos Pérez-Losada ${ }^{1-3 *}$, Jesse W Breinholt ${ }^{4}$, Manuel Aira ${ }^{5}$ and Jorge Domínguez ${ }^{5}$

${ }^{1}$ CIBIO, Centro de Investigação em Biodiversidade e Recursos Genéticos, Universidade do Porto, Campus Agrário de Vairão, 4485-661 Vairão, Portugal. ${ }^{2}$ Computational Biology Institute, George Washington University, Ashburn, VA 20147, USA

${ }^{3}$ Department of Invertebrate Zoology, US National Museum of Natural History, Smithsonian Institution, Washington, DC 20013, USA

${ }^{4}$ Florida Museum of Natural History, University of Florida, Gainesville, FL 32611, USA

${ }^{5}$ Departamento de Ecoloxía e Bioloxía Animal, Universidade de Vigo, E-36310, Spain

\begin{abstract}
Lumbricidae earthworms dominate agricultural lands and often natural terrestrial ecosystems in temperate regions in Europe. They impact soil properties and nutrient cycling, shaping plant community composition and aboveground food webs. The simplicity of the earthworm body plan has hampered morphology-based classifications and taxonomy; hence current research on Lumbricidae systematic relies mostly on molecular data from multiple or single locus [e.g., cytochrome oxidase subunit I (COI) barcodes] to infer evolutionary relationships, validate taxonomic groups and/or identify species. Here we use multiple nuclear and mitochondrial gene regions (including $\mathrm{COI}$ ) to generate updated maximum likelihood and Bayesian phylogenies of the family Lumbricidae. We then compare these trees to new $\mathrm{COI}$ trees to assess the performance of $\mathrm{COI}$ at inferring lumbricid inter-generic relationships.
\end{abstract}

Keywords: Barcode; COI; Earthworms; Lumbricidae; Taxonomy

\section{Introduction}

Lumbricidae earthworms account for $90 \%$ of the invertebrate biomass in temperate soils [1]. They exert a large impact on soil physical, chemical and biological properties and play a major role in animal food webs and plant composition [2]. Earthworms are model organisms in ecology, toxicology, physiology and reproductive biology, and generate great economic revenue and environmental benefits in vermiculture and vermicomposting $[1,3,4]$.

Lumbricids comprises $\sim 300$ known species, however, its taxonomy and classification has been hindered by the structural simplicity of the earthworm body plan $[5,6]$. As a result, no agreement exists between classifications and taxonomists about how the family should be subdivided. Only relatively recently earthworm specialists have begun to use molecular information and phylogenetic tools to validate and update Lumbricidae systematics. Phylogenetic analysis of DNA sequences has already proven useful to solve taxonomic questions within several lumbricid genera (e.g., Eisenia [7], Aporrectodea [5,8] and Postandrilus [9]).

Similarly, a few studies have also looked at the evolution of the family using one locus, two to three loci $[6,11,12]$, or many more loci (13 loci) and extensive sampling [13]. These and other studies have unanimously revealed that all the proposed Lumbricidae classifications and taxonomy do not hold and do not reflect evolutionary relationships, and that a robust and exhaustive phylogeny of the family is needed. Here we propose to expand our previous Lumbricidae dataset by adding a new genetic marker, the cytochrome oxidase subunit I (COI), for a total of 75 new earthworms. The COI gene has become the standard marker for DNA barcoding (i.e., molecular taxonomic identification) of most metazoans [14-16] including earthworms (e.g., Earthworm Barcode of Life; www.earthwormbol.org [17-19]. COI data couple with phylogenetic approaches have aided species identification $[15,17,19]$ and have provided valuable insights on the taxonomy and evolutionary relationships [7,15,20-23], phylogeography [20,21,24], and speciation $[25,26]$ of earthworms. Additionally, given the popularity of this marker and large size of the COI databases (constantly expanding through barcoding initiatives), COI has often been used alone to estimate earthworm phylogenies $[20,21,26]$. When compared with multilocus phylogenies, COI trees have proved to be a good proxy for estimating intrageneric $[7,10,12$,$] and sometimes intergeneric [10,12,26]$ evolutionary relationships in earthworms; however its potential for estimating intergeneric relationship across the Lumbricidae remains to be tested.

In the present study we update the genus-level multilocus phylogeny of the family Lumbricidae in Domínguez et al. [13] by adding the standard barcode region (COI). Then we test if this gene region is adequate for estimating intergeneric evolutionary relationships in the Lumbricidae and to assess discrepancies between gene(s) trees and Lumbricidae taxonomy.

\section{Material and Methods}

\section{Sampling}

Sampling of the family Lumbricidae for this study included 75 species representing 19 genera Figure 1. Earthworms were collected in Spain, Andorra, France, Italy, Germany, United Kingdom, Finland, Denmark, Poland, Romania, Hungary, Serbia, Israel, Austria, Turkey, South Africa, USA, Brazil, China and Vietnam. To root the Lumbricidae tree we used three representatives of the Criodrilidae and Hormogastridae. Specimens were identified as indicated in Domínguez et al. [13] and preserved in absolute ethanol and stored at $-20^{\circ} \mathrm{C}$. DNA extraction, amplification and sequencing.

Total genomic DNA was extracted using the DNAeasy Tissue kit (Qiagen). The mtDNA gene region corresponding to the cytochrome oxidase subunit I (COI) was amplified using primers in [27] and conditions in [5]. PCR products were purified using a MultiScreen $\mu 96$ (Millipore) PCR kit and sequenced bidirectional using an Applied Biosystems (ABI) 377XL automated sequencer. The ABI Big-dye

${ }^{*}$ Corresponding author: Dr. Marcos Pérez-Losada, Computational Biology Institute, George Washington University, Ashburn, VA 20147 USA, Tel: 5715530243; E-mail: mlosada323@gmail.com

Received November 04, 2014; Accepted November 27, 2014; Published November 30, 2014

Citation: Pérez-Losada M, Breinholt JW, Aira M, Domínguez J (2015) An Updated Multilocus Phylogeny of the Lumbricidae (Annelida: Clitellata: Oligochaeta) Earthworms. J Phylogen Evolution Biol 3: 140. doi:10.4172/2329-9002.1000140

Copyright: (c) 2015 Pérez-Losada M, et al. This is an open-access article distributed under the terms of the Creative Commons Attribution License, which permits unrestricted use, distribution, and reproduction in any medium, provided the original author and source are credited. 
Citation: Pérez-Losada M, Breinholt JW, Aira M, Domínguez J (2015) An Updated Multilocus Phylogeny of the Lumbricidae (Annelida: Clitellata: Oligochaeta) Earthworms. J Phylogen Evolution Biol 3: 140. doi:10.4172/2329-9002.1000140
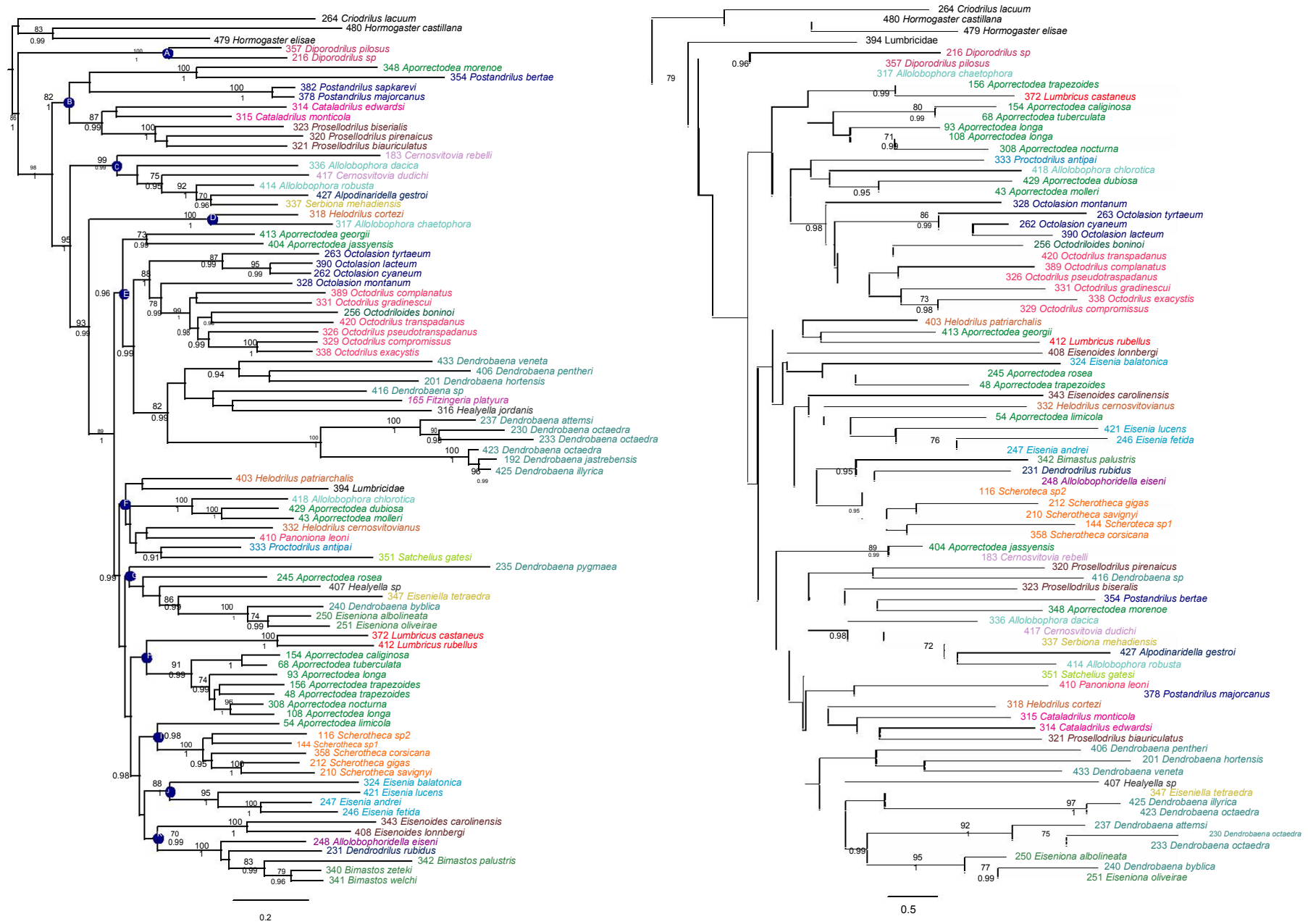

Figure 1: Multilocus (left) and COI (right) Lumbricidae maximum likelihood trees. Bootstrap proportions (if $\geq 70 \%$ ) and Bayesian posterior probabilities (if $\geq 95 \%$ ) are shown above and below the branches, respectively. Genera are colored with different colors.

Ready- Reaction kit was used following the standard cycle sequencing protocol, but with a 16th of the suggested reaction size.

\section{Phylogenetic analysis}

New 75 COI sequences were combined with nucleotide sequences from nuclear (28S rDNA and 18S rDNA) and mitochondrial [16S rDNA, $12 \mathrm{~S}$ rDNA, NADH dehydrogenase (ND1), cytochrome oxidase subunit II (COII) and tRNAs Asn, Asp, Val, Leu, Ala, Ser, and Leu)] genes in [13], rendering a final dataset comprised of 85 species and 30 genera. All gene regions were aligned in MAFFT v6 [28,29] under the global (G-INS-i) algorithm and default settings. JModelTest v1.0.1 [30] was used to select the appropriate model of evolution for each DNA partition under the Akaike Information Criterion AIC [31]. The general time reversible model of evolution [32], with proportion of invariable sites and gamma distribution, was selected for each partition.

Both maximum likelihood (ML) and Bayesian methods of phylogenetic inference were applied to both the COI dataset alone and all the genes combined (ALLgenes). ML analysis was performed in GARLI under default settings for the genetic algorithm, except that searchreps $=10$. Clade support was assessed using the nonparametric bootstrap procedure [33] with 1,000 bootstrap replicates.
Bayesian analysis coupled with Markov chain Monte Carlo (BMCMC) inference was performed in MrBayes v3.1.2 [34]. Four independent BMCMC analyses were run in the CIPRES Science Gateway portal [35], each consisting of four chains. Each Markov chain was started from a random tree and run for $2 \times 107$ cycles, with sampling every 1,000 th generation. Sequence evolution model parameters were estimated independently for each data partition starting as unknown variables with uniform default priors. Convergence and mixing were monitored using Tracer v1.5 [36]. All sample points prior to reaching stationary levels were discarded as burn-in. The posterior probabilities for individual clades obtained from separate analyses were compared for congruence and then combined and summarized on a $50 \%$ majority- rule consensus tree. Confidence in our best hypotheses of phylogenetic relationships was tested under both likelihood and Bayesian frameworks. Likelihood topological tests were conducted using the Shimodaira and Hasegawa (S-H) [37] test as implemented in RAxML v7.2.0 [38]. Bayesian topological tests were performed as described in Huelsenbeck et al. [39].

\section{Results and Discussion}

ML and Bayesian trees Figure 1 for COI and ALLgenes showed minor topological differences between phylogenies of the same dataset, but no inconsistency (i.e., highly supported clades composed 
Citation: Pérez-Losada M, Breinholt JW, Aira M, Domínguez J (2015) An Updated Multilocus Phylogeny of the Lumbricidae (Annelida: Clitellata: Oligochaeta) Earthworms. J Phylogen Evolution Biol 3: 140. doi:10.4172/2329-9002.1000140

Page 3 of 4

of different taxa) was detected between them. However, COI and ALLgenes ML and Bayesian trees were significantly different between datasets $(\mathrm{P}<0.001$ for the $\mathrm{S}-\mathrm{H}$ test; $\mathrm{P}<0.001)$, showing major differences in their topologies with some clades being inconsistent between the two datasets (e.g., 404 Aporrectodea jasseyensis and 183 Cernosvitovia rebelli; 156 Aporrectodea trapezoids and 372 Lumbricus castaneus; 248 Allolobophoridella eiseni, 342 Bimastus palustris and 231 Dendrodrilus rubidus). These differences highlight the low power (i.e., phylogenetic signal) of COI to solve intergeneric relationships in the Lumbricidae (as suggested in [10]), unless combined with other genes [12]. In the ALLgenes trees, the 28 analyzed Lumbricidae genera were distributed in 11 clades (A to K in Figure 1) as in Domínguez et al. [13] and support for some clades was increased in the new tree.

No major differences were observed between both studies for the backbone of the Lumbricidae tree, although some minor differences including the position of 336 Allolobophora dacica, 245 Aporrectodea rosea and 407 Healyella sp., and relationships among a few taxa in clades B, E, F, H and I were observed. No inconsistent topological differences were observed among trees. The monophyly of Lumbricidae genera represented species was confirmed for Bimastos, Diporodrilus, Eiseniona,Eisenia, Eisenoides, Lumbricus, Prosellodrilus, Scherotheca and Cataladrilus (this analysis); while Allolobophora, Aporrectodea, Cernosvitovia, Dendrobaena, Healyella, Helodrilus, Octodrilus, Octolasion, and Postandrilus were still para or polyphyletic as currently defined, in agreement with assemblages in Domínguez et al. [13] and Pérez- Losada et al. [10]. Within the non-monophyletic taxa, some genera were scattered throughout the phylogeny falling in different singular or polyspecies clades (Allolobophora, Aporrectodea, Healyella and Helodrilus), while others were more closely clustered, although intermixed with species from other genera (Cernosvitovia, Dendrobaena, Octodrilus, Octolasion and Postandrilus). Systematically, these topological rearrangements suggest that the more dispersed genera may have to be split into new genera, while the less dispersed genera may only require to be redefined to accommodate new species.

The ALLgenes trees also confirmed that Dendrobaena octaedra may constitute a species complex. Overall, our new analyses reinforce the statement made by others [10-13] of that the Lumbricidae taxonomy needs extensive revision, and that phylogenetic relatedness must be used to delineate the next Lumbricidae classification.

\section{Conclusions}

This study presents a well-supported phylogeny of the family Lumbricidae and updates previous phylogenetic analyses in Domínguez et al. [13]. Our comparison of multilocus and COI trees highlights the low phylogenetic signal of COI to infer lumbricid intergeneric relationships, unless combined with other genes. If used alone, this gene should only be used for species identification (barcoding) and assessing evolutionary relationships below the genus level. Our results also confirm that the Lumbricidae taxonomy needs extensive revision.

\section{Acknowledgements}

This research was funded by the Spanish Ministerio de Ciencia e Innovación (projects CGL2006-11928 and CTM2009-08477), Xunta de Galicia (CN2012/305), and a "Projeto de investigação Exploratória" from the FCT Investigator Program to MP-L. We gratefully acknowledge Grzegorz Gryziak, Konstantin Gongalsky, Jari Haimi, Martin Holmstrup, Mervi Niemen, Nicolas Bottinelli, Veikko Huhta, Pascal Jouquet, Sonja Migge-Kleian, Yvan Capowiez, Danuta Plisko, Marta Novo, Darío Díaz Cosín and Alexander Feijoo for generously providing earthworm samples. We also thank Maigualida Ricoy, Cristina Lazcano, María Gómez, Marta Lores, Cristóbal Pérez, Pablo González and Fernando Monroy for collaborating in collecting earthworms to complete this study and Alberto Velando for critical discussions and helpful revisions of previous drafts of the manuscript.

\section{References}

1. Edwards CA (2004) Earthworm Ecology. (Edn 2) CRC Press, Boca Raton, Florida.

2. Lavelle P, Spain AV (2001) Soil ecology. Kluwer Academic Publishers Dordrecht, The Netherlands.

3. Domínguez J, Aira M, Gómez Brandón M (2010) Vermicomposting: earthworms enhance the work of microbes. In: Insam, H., Franke-Whittle, I., Goberna, M. Microbes at work: from wastes to resources. Springer, Berlin Heidelberg, pp. 93- 114.

4. Dominguez J, Velando A (2013) Sexual selection in earthworms: Mate choice sperm competition, differential allocation and partner manipulation. Appl Soil Ecol 69: 21-27.

5. Pérez-Losada M, Ricoy M, Domínguez J, Marshall J (2009) Phylogenetic assessment of the earthworm Aporrectodea caliginosa species complex (Oligochaeta, Lumbricidae) based on mitochondrial and nuclear DNA sequences. Mol Phylogenet Evol 52: 293-302.

6. Pop AA, Wink M, Pop VV (2003) Use of 18S, 16S rDNA and cytochrome c oxidase sequences in earthworm taxonomy (Oligochaeta, Lumbricidae). Pedobiologia 47: 428-433.

7. Pérez-Losada M, Eiroa J, Mato S, Domínguez J (2005) Phylogenetic species delimitation of the earthworms Eisenia fetida (Savigny, 1826) and Eisenia andrei Bouché, 1972 (Oligochaeta, Lumbricidae) based on mitochondrial and nuclear DNA genes. Pedobiologia 49: 317-324.

8. Fernandez R, Almodovar A, Novo M, Simancas B, Cosin DJD (2012) Adding complexity to the complex: New insights into the phylogeny, diversification and origin of parthenogenesis in the Aporrectodea caliginosa species complex (Oligochaeta, Lumbricidae). Mol Phylogenet Evol 64: 368-379.

9. Pérez-Losada M, Breinholt JW, Porto PG, Aira M, Domínguez J (2011) An earthworm riddle: systematics and phylogeography of the Spanish lumbricid Postandrilus. PLoS One 6: e28153.

10. Pérez-Losada M, Bloch R, Breinholt JW, Pfenninger M, Dominguez J (2012) Taxonomic assessment of Lumbricidae (Oligochaeta) earthworm genera using DNA barcodes. Eur J Soil Biol 48: 41-47.

11. Briones MJI, Moran P, Posada D (2009) Are the sexual, somatic and genetic characters enough to solve nomenclatural problems in lumbricid taxonomy? Soil Biol Biochem 41: 2257-2271.

12. Klarica J, Kloss-Brandstatter A, Traugott M, Juen A (2012) Comparing four mitochondrial genes in earthworms - Implications for identification, phylogenetics, and discovery of cryptic species. Soil Biol Biochem 45: 23-30.

13. Domínguez J, Aira M, Breinholt JW, Stojanovic M, James SW, et al. (2014) Underground evolution: new roots for the old tree of lumbricid earthworms. Mol Phylogenet Evol 83: 7-19.

14. Hebert PD, Cywinska A, Ball SL, deWaard JR (2003) Biological identifications through DNA barcodes. Proc Biol Sci 270: 313-321.

15. Richard B, Decaëns T, Rougerie R, James SW, Porco D, et al. (2010) Reintegrating earthworm juveniles into soil biodiversity studies: species identification through DNA barcoding. Mol Ecol Resour 10: 606-614

16. Savolainen V, Cowan RS, Vogler AP, Roderick GK, Lane R (2005) Towards writing the encyclopedia of life: an introduction to DNA barcoding. Philos Trans R Soc Lond B Biol Sci 360: 1805-1811.

17. Chang $\mathrm{CH}$, Rougerie $\mathrm{R}$, Chen JH, (2009) Identifying earthworms through DNA barcodes: Pitfalls and promise. Pedobiologia 52: 171-180.

18. Decaëns T, Porco D, Rougerie R, Brown GG, James SW (2013) Potential of DNA barcoding for earthworm research in taxonomy and ecology. Appl Soil Ecol 65: 35-42.

19. Huang J, Xu Q, Sun ZJ, Tang GL, Su ZY (2007) Identifying earthworms through DNA barcodes. Pedobiologia 51: 301-309.

20. Chang $\mathrm{CH}$, Chen JH (2005) Taxonomic status and intraspecific phylogeography of two sibling species of Metaphire (Oligochaeta: Megascolecidae) in Taiwan. Pedobiologia 49: 591-600.

21. Chang CH, Lin SM, Chen JH (2008) Molecular systematics and phylogeography of the gigantic earthworms of the Metaphire formosae species group (Clitellata, Megascolecidae). Mol Phylogenet Evol 49: 958-968.

22. Pop AA, Csuzdi C, Wink M, Pop VV (2005) An attempt to reconstruct the 
Citation: Pérez-Losada M, Breinholt JW, Aira M, Domínguez J (2015) An Updated Multilocus Phylogeny of the Lumbricidae (Annelida: Clitellata: Oligochaeta) Earthworms. J Phylogen Evolution Biol 3: 140. doi:10.4172/2329-9002.1000140

molecular phylogeny of the genus Allolobophora Eisen, 1874 (sensu lato, Pop, 1941) using 16S rDNA and COI sequences (Oligochaeta, Lumbricidae). In: Pop VV, Pop AA, Advances in Earthworm Taxonomy II. Cluj University Press, ClujNapoca, pp. 155-166.

23. Pop AA, Csuzdi C, Wink M, Pop VV (2008) Molecular taxonomy and phylogeny of the genera Octolasion Örley,1885, Octodrilus Omodeo,1856 and Octodriloides Zicsi, 1986 (Oligochaeta, Lumbricidae) based on nucleotide sequences of mitochondrialcek, 16ST., rDNACardet,andP.COI(Edsgenes). In: Pavlí Advances in Earthworm Taxonomy III. Environment Service of the Ministry of Agriculture, Natural Resources and Environment of the Republic of Cyprus, Nicosia, pp. 109-125.

24. Minamiya Y, Yokoyama J, Fukuda T (2009) A phylogeographic study of the Japanese earthworm, Metaphire sieboldi (Horst, 1883) (Oligochaeta: Megascolecidae): Inferences from mitochondrial DNA sequences. Eur J Soil Biol 45: 423-430.

25. King RA, Tibble AL, Symondson WO (2008) Opening a can of worms: unprecedented sympatric cryptic diversity within British lumbricid earthworms. Mol Ecol 17: 4684-4698.

26. Novo M, Almodovar A, Diaz-Cosin DJ (2009) High genetic divergence of hormogastrid earthworms (Annelida, Oligochaeta) in the central Iberian Peninsula: evolutionary and demographic implications. Zool Scripta 38: 537552.

27. Folmer O, Black M, Hoeh W, Lutz R, Vrijenhoek R (1994) DNA primers for amplification of mitochondrial cytochrome $\mathrm{C}$ oxidase subunit I from diverse metazoan invertebrates. Mol Mar Biol Biotechnol 3: 294-299.

28. Katoh K, Kuma K, Toh H, Miyata T (2005) MAFFT version 5: improvement in accuracy of multiple sequence alignment. Nucleic Acids Res 33: 511-518.
29. Katoh K, Toh H (2008) Recent developments in the MAFFT multiple sequence alignment program. Brief Bioinform 9: 286-298.

30. Posada D (2009) Selection of models of DNA evolution with jModelTest Methods Mol Biol 537: 93-112.

31. Posada D, Buckley TR (2004) Model selection and model averaging in phylogenetics: advantages of akaike information criterion and bayesian approaches over likelihood ratio tests. Syst Biol 53: 793-808.

32. Tavare S (1986) Some probabilistic and statistical problems in the analysis of DNA sequences. Am Math Soc Providence RI 17: 57-86.

33. Felsenstein J (1985) Confidence limits on phylogenies: an approach using the bootstrap. Evolution 39: 783-791.

34. Ronquist F, Huelsenbeck JP (2003) MrBayes 3: Bayesian phylogenetic inference under mixed models. Bioinformatics 19: 1572-1574.

35. Miller MA, Pfeiffer W, Schwartz T (2010) Creating the CIPRES Science Gateway for inference of large phylogenetic trees. Gateway Computing Environments Workshop (GCE), New Orleans, LA, pp. 1-8.

36. Rambaut A, Drummond AJ (2009) Tracer: MCMC trace analysis tool. Institute of Evolutionary Biology, Edinburgh.

37. Shimodaira H, Hasegawa M, (1999) Multiple comparisons of log-likelihoods with applications to phylogenetic inference. Mol Biol Evol 16: 1114-1116.

38. Stamatakis A, Hoover P, Rougemont J (2008) A rapid bootstrap algorithm for the RAxML Web servers. Syst Biol 57: 758-771.

39. Huelsenbeck JP, Larget B, Miller RE, Ronquist F (2002) Potential applications and pitfalls of Bayesian inference of phylogeny. Syst Biol 51: 673-688. 